\title{
Quantitation by Portable Gas Chromatography: Mass Spectrometry of VOCs Associated with Vapor Intrusion
}

\author{
Justin D. Fair, ${ }^{1}$ William F. Bailey, ${ }^{2}$ Robert A. Felty, ${ }^{3}$ Amy E. Gifford, ${ }^{3}$ Benjamin Shultes, ${ }^{3}$ \\ and Leslie H. Volles ${ }^{3}$
}

${ }^{1}$ Department of Chemistry, Indiana University of Pennsylvania, Indiana, PA 15701, USA

${ }^{2}$ Department of Chemistry, University of Connecticut, Storrs, CT 06269, USA

${ }^{3}$ INFICON, Inc., 2 Technology Place, East Syracuse, NY 13057, USA

Correspondence should be addressed to Justin D. Fair, j.fair@iup.edu

Received 6 July 2010; Revised 24 August 2010; Accepted 31 August 2010

Academic Editor: Hian Kee Lee

Copyright (c) 2010 Justin D. Fair et al. This is an open access article distributed under the Creative Commons Attribution License, which permits unrestricted use, distribution, and reproduction in any medium, provided the original work is properly cited.

\begin{abstract}
Development of a robust reliable technique that permits for the rapid quantitation of volatile organic chemicals is an important first step to remediation associated with vapor intrusion. This paper describes the development of an analytical method that allows for the rapid and precise identification and quantitation of halogenated and nonhalogenated contaminants commonly found within the ppbv level at sites where vapor intrusion is a concern.
\end{abstract}

\section{Introduction}

Indoor air quality has become an ever increasing topic of interest in light of reports detailing building-related illnesses ("sick building syndrome") that produce symptoms such as upper respiratory diseases, headaches, dizziness, and fatigue [1]. Indeed, the typical person spends approximately $90 \%$ of his day indoors [2]. A number of models have been proposed to address the processes in which indoor air contamination occurs via vapor intrusion [3-6]. In addition, environmental factors have been identified to include the following: proximity to source, presence of shallow ground water, soil type, fractured bedrock, chemical degradation (or oxidation), building construction style, as well as floor/utility line(s) condition [7]. Petroleum-based products and chlorinated hydrocarbons, as well as a variety of other volatile organic compounds (VOCs), can drift great distances above local water tables and enter dwellings via vapor intrusion from sources such as industrial sites or landfills [8-12].

Once an instance of vapor intrusion has been identified, monitoring the volatile organic chemicals contained in indoor air may be accomplished by following the compendium methods of the US EPA [13-15]; thus assisting to survey and mitigate the known hazard(s). These methods, which involve both passive and active sampling techniques, require time-consuming concentration periods and incorporate off-site laboratory analysis of multiple samples resulting in delayed overall analysis time [16]. The Massachusetts Department of Environmental Protection is one of a handful of US agencies to provide guidelines for long-term exposure to contaminated indoor air. Their defined limits, ranging from 0.001 to 187 ppbv per individual contaminate, provide the necessary guidance to incident commanders or super fund site coordinators to determine if a building is indeed fit to occupy once a site has been identified to suffer from sick building syndrome [17].

Field-portable instrumentation has been shown to offer rapid analysis of samples on site. Performing the chemical analysis onsite assists in eliminating sample integrity issues that may arise when volatile and hazardous samples are shipped long distances [18-20]. One field-portable gas chromatography/mass spectrometry (GC/MS) instrument in particular (Figure 1) utilizes a microconcentrator to sample ambient air at the ppbv level [21-24]. A previous modification to the instrument's existing sample flow path provided a means to identify multiple VOCs simultaneously with little to no analyte resolution in the total ion chromatogram (TIC). The entire sampling and analysis time takes less than 


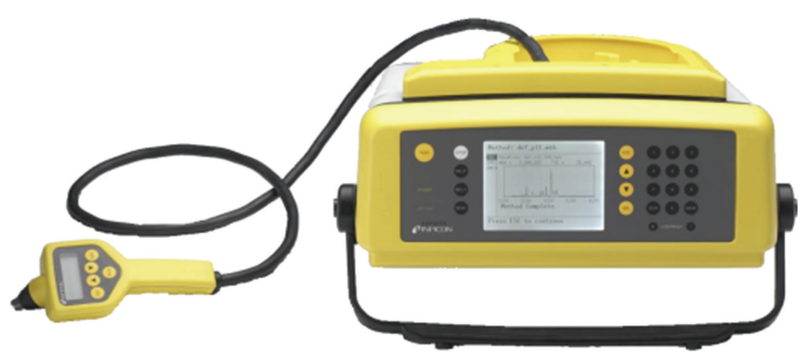

Figure 1: The HAPSITE Smart GC/MS system.

TABle 1: Composition of standard mix 1 used for construction of calibration curves.

\begin{tabular}{lc}
\hline Compound & Concentration in $\mathrm{CH}_{3} \mathrm{OH}(\mu \mathrm{g} / \mathrm{mL})$ \\
\hline Benzene & 160 \\
Carbon tetrachloride & 314 \\
Ethyl chloride & 132 \\
$Z$-1,2-Dichloroethene & 99.0 \\
$E$-1,2-Dichloroethene & 99.0 \\
Methylene chloride & 174 \\
Trichloroethylene & 273 \\
Vinyl chloride & 128 \\
Tetrachloroethylene & 340 \\
Toluene & 189 \\
$m$-Xylene & 72.7 \\
$p$-Xylene & 72.7 \\
$o$-Xylene & 72.7 \\
\hline
\end{tabular}

3 minutes [25]. This initial proof of concept demonstrated that shortened sample collection and sample run times did not hinder the portable mass spectrometer's identification of organic compounds. The present study was designed to evaluate the ability of this instrument to quantitate a mixture of VOCs commonly associated with vapor intrusion at the low ppbv level in accordance with current analytical methods [14].

\section{Experimental Section}

2.1. Reagents and Standards. Analytical grade standards in methanol solution (mix 1 and mix 2) were purchased from SPEX CertiPrep Inc. (Metuchen, NJ, USA). All standards purchased from SPEX CertiPrep Inc. arrived with a certificate of analysis detailing their final concentrations. The chemical standards used herein were chosen as they are "the primary sources of vapor intrusion problems in the United States" [7]. Nitrogen, UHP grade, was purchased from Airgas and used to dilute the standard mixes in Tedlar bags, purchased from SKC Inc. (Eighty Four, PA, USA). The samples used for construction of calibration curves were prepared by injecting $10.0 \mu \mathrm{L}$ of standard mix 1 (Table 1) into a Tedlar bag containing $1.00 \mathrm{~L}$ of UHP nitrogen. The samples used for the method detection limits (MDLs) determination were prepared by injecting $10.0 \mu \mathrm{L}$ of standard mix 2 (Table 2) into a Tedlar bag containing $1.00 \mathrm{~L}$ of UHP nitrogen.
2.2. Portable GC Modifications. The gas chromatograph/ mass spectrometer was modified as previously described [25]. However, instead of employing a Tenax microconcentrator as done previously, a TriBed microconcentrator, supplied by Inficon Inc. (East Syracuse, NY, USA), consisting of a thin-walled glass tube, packed with three layers of a proprietary blend of absorbents and wrapped with a heating element, was used to concentrate samples. This seemingly minor modification was essential for the trapping of the entire sample mixture, allowing complete sample adsorption for quantitation. The use of the multibed adsorbent, instead of a single absorbent, packed in order of increasing sorbent strength, provides adsorption of a wider range of compound classes as well as volatility ranges [26]. The sample flow path used in this study is depicted schematically in Figure 2.

2.3. TriBed Microconcentrator Conditioning. The concentrator was cleaned using the following method: a $10 \mathrm{~s}$ line purge, a $3 \mathrm{~s}$ concentrator fill, a $15 \mathrm{~s}$ foreflush, an $11 \mathrm{~s}$ predesorb, a $30 \mathrm{~s}$ desorb, a $60 \mathrm{~s}$ foreflush, and a $124 \mathrm{~s}$ backflush (total $253 \mathrm{~s}$ run time). The concentrator was deemed to be "clean" when the TIC plot had a maximum value of $\leq 500,000$ counts. If the maximum TIC count exceeded this value, the concentrator was repeatedly recleaned until this requirement was met.

2.4. Portable GC Conditions. The following method was used for both blank runs and analyses of VOC samples: a $10 \mathrm{~s}$ line purge, a $15 \mathrm{~s}$ concentrator fill, a $1 \mathrm{~s}$ foreflush, a $20 \mathrm{~s}$ backflush, an $8 \mathrm{~s}$ pre-desorb, a $30 \mathrm{~s}$ desorb, a $43 \mathrm{~s}$ foreflush, and a $23 \mathrm{~s}$ backflush (total run time of $125 \mathrm{~s}$ ). A mass range of 45 to 250 was selected, and the following temperatures were set: column, $65^{\circ} \mathrm{C}$; $\mathrm{GC} / \mathrm{MS}$ membrane, $65^{\circ} \mathrm{C}$; valve oven, $65^{\circ} \mathrm{C}$; probe, $40^{\circ} \mathrm{C}$. A $15 \mathrm{~s}$ filament delay time was used to elute any ambient gasses such as oxygen, nitrogen, and carbon dioxide.

2.5. Linear Range and Method Detection Limit. The conditions outlined above were used in the creation of calibration curves for each analyte. A linear regression analysis of the average target-ion areas from four replicate runs at each concentration listed in Table 3 was used to construct a calibration curve for each of the analytes. For each sample, a concentrator clean, concentrator blank, and analytical run were performed sequentially. Calibration curves were constructed such that each curve was forced through the origin.

Method detection limits were determined by diluting $10.0 \mu \mathrm{l}$ of each sample (Table 2) in $1.00 \mathrm{~L}$ of nitrogen. For each sample, a concentrator clean, concentrator blank, and analytical run were performed sequentially. Nine consecutive runs were used to evaluate each analyte's average concentration, variance, standard deviation, and method detection limit as described in the US Code of Federal Regulations (40CFR136, Appendix B).

The calibration curve allowed quantitative library searching using the NIST mass spectral database. The following parameters were used in the NIST peak search: search window of $45 \mathrm{~s}$, minimum reconstructed ion chromatogram (RIC) area of 28,000 , minimum TIC area of 28,000 , window 
TABLE 2: Composition of standard mix 2 used for method detection limits determination.

\begin{tabular}{lcc}
\hline Compound & Concentration in $\mathrm{CH}_{3} \mathrm{OH}(\mu \mathrm{g} / \mathrm{mL})$ & Concentration in $\mathrm{N}_{2}(\mathrm{ppbv})$ \\
\hline Benzene & 1.8 & 5.6 \\
Carbon tetrachloride & 3.5 & 5.6 \\
Ethyl chloride & 23.1 & 87.7 \\
$($ E/Z)-1,2-Dichloroethene & $4.4(2.2$ of each isomer $)$ & 11 \\
Methylene chloride & 1.9 & 5.5 \\
Trichloroethylene & 3.0 & 5.5 \\
Vinyl chloride & 22.4 & 87.6 \\
Tetrachloroethylene & 3.8 & 5.6 \\
Toluene & 2.1 & 5.6 \\
$o, m$, and $p$-Xylene & $2.4(0.8$ of each isomer $)$ & 5.5 \\
\hline
\end{tabular}

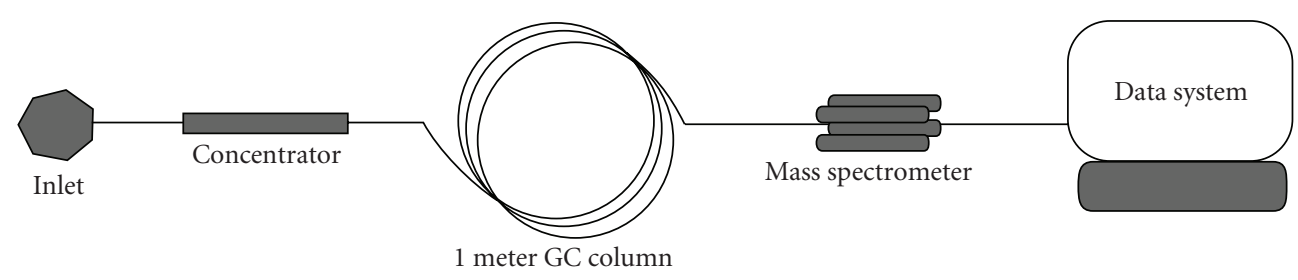

FIGURE 2: Schematic of the GC/MS with final modifications.

expand factor of 0.05 , minimum width of 7 , minimum fit of 0.03 , peak resolution of 5 , maximum width of 70 , minimum purity of 0.01 , noise level mult of 2 , and precedence level of 0 . The following parameters were used in the automated mass spectral deconvolution and identification system search: analysis type simple, low mass of 45 , high mass of 250 , sensitivity of 30 , resolution medium, and minimum match factor of 70 .

2.6. Audit Accuracy and Precision. Audit accuracy samples were prepared from individual standards in methanol solution supplied by SPEX CertiPrep Inc. (Metuchen, NJ, USA). A set of five randomly selected analytes, representing onehalf of the total compounds of interest, were chosen to verify the accuracy of the calibration curve: xylenes, toluene, methylene chloride, tetrachloroethylene, and trichloroethylene. For each sample, a concentrator clean, concentrator blank, and analytical run were performed sequentially. Four consecutive runs were used to determine the accuracy and precision of the calibration curve.

2.7. Breakthrough Times. A clean TriBed microconcentrator was attached between the end of the instrument's probe and a Tedlar sample bag containing $10.0 \mu \mathrm{L}$ of sample mix 1 (Table 1) in $1.00 \mathrm{~L}$ of nitrogen. The configuration is illustrated in Figure 3. The Tedlar bag and concentrator were connected by a $0.4 \mathrm{~cm}$ section of Tygon tubing; sample flow rate was measured to be $99 \mathrm{~mL} / \mathrm{min}$. Each run consisted of a $10 \mathrm{~s}$ line purge and a $15 \mathrm{~s}$ concentrator fill to provide for a total concentration time for concentrator (2) of $25 \mathrm{~s}$ for each analytical run. As each successive run was performed, the bleed-through was caught by the main concentrator (1) and identified by the GC/MS system.

\section{Results and Discussion}

3.1. Concentrator Selection. The TriBed microconcentrator was chosen for its ability to trap low molecular weight and low boiling analytes. The TriBed microconcentrator employs a bed consisting of multiple adsorbents of varying polarity to trap a wide range of analytes. The total ion chromatogram obtained from the 13 analytes in mix 1 (Table 1) is displayed in Figure 4. It might be noted that there is a small shoulder at $\sim 30$ s corresponding to vinyl chloride and ethyl chloride. In our experience, these two volatile analytes were difficult to trap using unisorbant concentrators such as the Tenax microconcentrator. The use of the multibed concentrator was essential in allowing the quantitation of all analytes in this study.

3.2. Method Validation. A series of several calibration concentrations from 49.91 to $501.5 \mathrm{ppbv}$ (Table 3 ) were sampled in four replicate runs at each concentration. A representative TIC and an RIC from a typical analysis of the 13 analytes in mix 1 (Table 1) are illustrated in Figures 4 and 5, respectively. The target ion, retention time, correlation coefficient, percent relative standard deviation, linear range, average response factor, and method detection limit for each analyte are summarized in Table 4.

It should be noted that all correlation coefficients are greater than 0.985 . Moreover, the linear range for all but three of the analytes ( $v i z$, ethyl chloride, methylene chloride, and vinyl chloride) was $0-500 \mathrm{ppbv}$. The percent relative standard deviation (\% RSD) ranged from $0.76 \%$ to $17.30 \%$. The low-average response factor observed for ethyl chloride is a consequence of using a mass $(\mathrm{m} / \mathrm{z})$ of 66 rather than $\mathrm{m} / \mathrm{z}$ $=64$ for quantitation of this analyte; $\mathrm{m} / \mathrm{z}=66$ was selected to provide clean calibration profiles while avoiding interference from other analytes in this study. 
TABLE 3: Concentrations used to construct calibration curves.

\begin{tabular}{|c|c|c|c|c|c|}
\hline \multirow{2}{*}{$\begin{array}{l}\text { Compound } \\
\text { Benzene }\end{array}$} & \multicolumn{5}{|c|}{ Concentration in $N_{2}$ (ppbv) } \\
\hline & 50.08 & 125.2 & 250.4 & 375.6 & 500.8 \\
\hline Carbon tetrachloride & 49.91 & 124.8 & 249.6 & 374.3 & 499.1 \\
\hline Ethyl chloride & 50.03 & 125.1 & 250.2 & 375.2 & 500.3 \\
\hline (E/Z)-1,2-Dichloroethene & 49.94 & 124.9 & 249.7 & 374.5 & 499.4 \\
\hline Methylene chloride & 50.09 & 125.2 & 250.5 & 375.7 & 500.9 \\
\hline Trichloroethylene & 50.04 & 125.1 & 250.2 & 375.3 & 500.4 \\
\hline Vinyl chloride & 50.07 & 125.2 & 250.4 & 375.6 & 500.8 \\
\hline Tetrachloroethylene & 50.13 & 125.3 & 250.7 & 376.0 & 501.3 \\
\hline Toluene & 50.12 & 125.4 & 250.8 & 376.1 & 501.5 \\
\hline Xylene $(o / m / p)$ & 49.97 & 124.9 & 249.9 & 374.8 & 499.7 \\
\hline
\end{tabular}

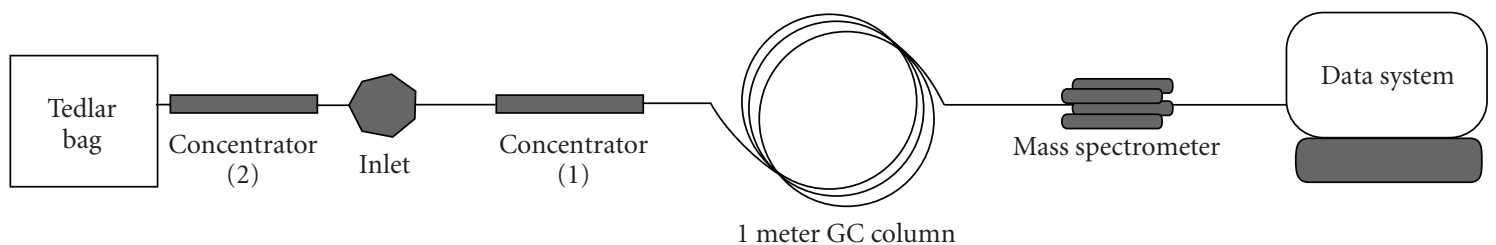

FIGURE 3: Configuration used for breakthrough study.

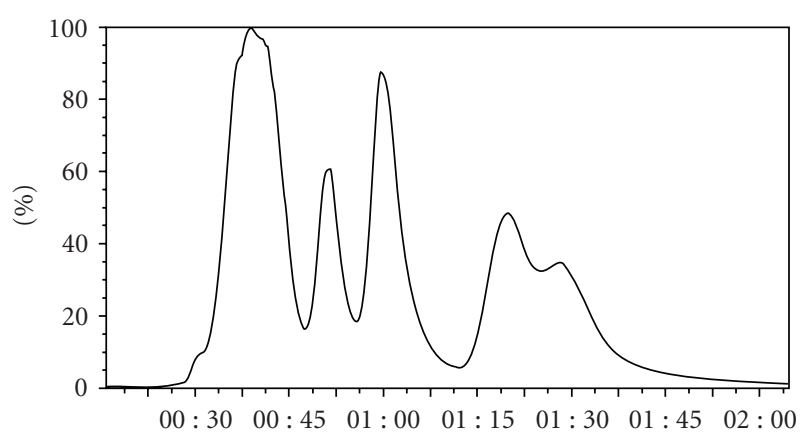

Figure 4: Total ion chromatogram (TIC) of analytes in mix 1 (Table 1) using a TriBed microconcentrator.

The method detection limit (MDL) for each analyte was evaluated and they are summarized in Table 4 in units of $\mathrm{ppbv}$ and $\mathrm{mg} / \mathrm{m}^{3}$. The MDL can also be viewed as the mass of each analyte in the total sample and these are also summarized in Table 4 for each analyte. The goal of this project was to have a total sampling and analysis time of less than $3 \mathrm{~min}$; however, it should be noted that the MDL may be lowered with longer concentration times since the MDL is proportional to the sampling time. Thus, a majority of the MDL values can be brought below a $0.5 \mathrm{ppbv}$ level using concentration times ranging from $30 \mathrm{~s}$ to $90 \mathrm{~s}$.

3.3. Determination of Audit Accuracy. The precision and accuracy of the newly determined analytical method were determined using randomly chosen analytes. The results of this method validation can be compared to the US EPA's Compendium Method TO-15 [14] that contains current indoor air monitoring guidelines as well as performance

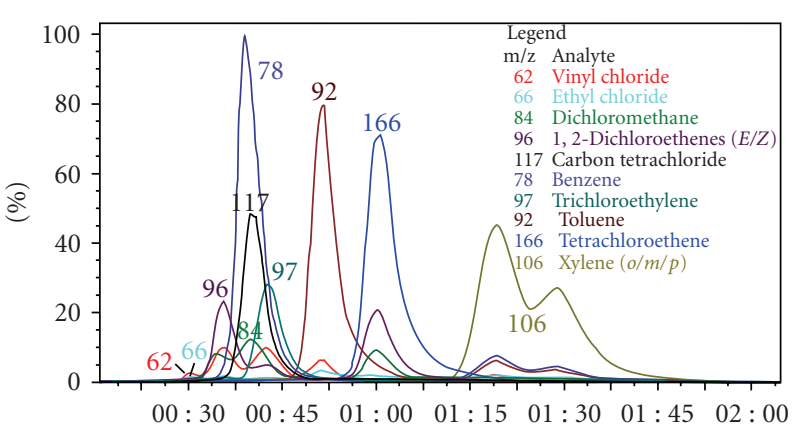

FIgURE 5: Reconstructed ion chromatogram (RIC) from the TIC illustrated in Figure 4.

criterion for replicate precision and audit accuracy. Thus, the replicate precision was found by calculating the absolute difference between replicate measurements. Current indoor air methods are required to have a replicate precision with a percent difference less than or equal to $25 \%$ [14]. The audit accuracy, the degree of agreement with audit samples, was calculated by finding the percent difference between the nominal concentration and that of the audit sample. Current indoor air methods are required to have an audit accuracy less than or equal to $30 \%$ [14]. The concentration averaged over 4 replicate runs, along with the percent difference for the replicate precision and audit accuracy, are summarized in Table 5. The replicate precision ranged from $2 \%$ to $5 \%$ and the percent audit accuracy ranged from $3 \%$ to $26 \%$. Both the replicate precision and the audit accuracy are within current US EPA method guidelines for the monitoring of indoor air.

3.4. Breakthrough Study. Using the instrument configuration depicted in Figure 3 and a sequence of analytical runs 
TABLE 4: Method validation results.

\begin{tabular}{|c|c|c|c|c|c|c|c|c|c|}
\hline \multirow{2}{*}{ Compound } & \multirow{2}{*}{ Mass $(\mathrm{m} / \mathrm{z})$} & \multirow{2}{*}{$t_{R}^{\mathrm{a}}(\mathrm{s})$} & \multirow{2}{*}{$R^{2}$} & \multirow{2}{*}{$\% \mathrm{RSD}$} & \multirow{2}{*}{ Linear Range (ppbv) } & \multirow{2}{*}{ Avg. Response Factor } & \multicolumn{3}{|c|}{ MDL } \\
\hline & & & & & & & ppbv & $\mathrm{mg} \mathrm{m}^{-3}$ & ng sample ${ }^{-1 b}$ \\
\hline Benzene & 78 & 41 & 0.999 & 5.9 & $0-501$ & $9.03 \times 10^{4}$ & 3.2 & 10 & 0.25 \\
\hline Carbon tetrachloride & 117 & 42 & 0.999 & 2.5 & $0-499$ & $5.11 \times 10^{4}$ & 2.7 & 11 & 0.28 \\
\hline$(E / Z)$-1,2-Dichloroethylene & 96 & 36 & 0.987 & 11.3 & $0-499$ & $2.40 \times 10^{4}$ & 12.1 & 47.9 & 1.19 \\
\hline Ethyl chloride & 66 & 34 & 0.990 & 17.3 & $0-250$ & $4.14 \times 10^{3}$ & 16.5 & 43.6 & 1.08 \\
\hline Methylene chloride & 84 & 35 & 0.985 & 14.1 & $0-251$ & $1.53 \times 10^{4}$ & 27.6 & 96.0 & 2.38 \\
\hline Trichloroethylene & 97 & 45 & 0.998 & 6.8 & $0-500$ & $2.85 \times 10^{4}$ & 2.1 & 11 & 0.27 \\
\hline Tetrachloroethylene & 166 & 63 & 0.999 & 0.8 & $0-501$ & $9.81 \times 10^{4}$ & 0.7 & 4 & 0.1 \\
\hline Toluene & 92 & 54 & 0.998 & 6.8 & $0-502$ & $7.78 \times 10^{4}$ & 1.8 & 6.9 & 0.17 \\
\hline Vinyl chloride & 62 & 34 & 0.999 & 3.3 & $0-250$ & $1.50 \times 10^{4}$ & 13 & 33 & 0.81 \\
\hline$o, m, p$-Xylenes & 106 & $82^{\mathrm{c}}$ & 0.999 & 5.3 & $0-500$ & $6.58 \times 10^{4}$ & 3.2 & 13 & 0.34 \\
\hline
\end{tabular}

a Retention time. ${ }^{\mathrm{b}}$ Sample concentration time of $15 \mathrm{~s}$ at a $99 \mathrm{~cm}^{3} \mathrm{~min}^{-1}$ flow rate. ${ }^{\mathrm{c}} \mathrm{A} t_{R}$ of $82 \mathrm{~s}$ with a window wide enough to include all isomeric xylenes.

TABle 5: Audit accuracy.

\begin{tabular}{lcccc}
\hline Compound & $\begin{array}{c}\text { Concentration of } \\
\text { standard (ppbv) }\end{array}$ & $\begin{array}{c}\text { Calculated } \\
\text { concentration } \\
\text { (ppbv) }\end{array}$ & $\begin{array}{c}\text { Replicate precision } \\
\text { (\% difference) }\end{array}$ & $\begin{array}{c}\text { Percent audit } \\
\text { accuracy }(\% \\
\text { difference) }\end{array}$ \\
\hline Methylene chloride & 173 & 128 & 2.52 & 25.9 \\
Trichloroethylene & 45.8 & 40.6 & 4.04 & 11.3 \\
Tetrachloroethylene & 16.2 & 13.1 & 3.16 & 2.09 \\
Toluene & 74.3 & 88.3 & 4.71 & 19.6 \\
$o, m, p$-Xylenes & 89.4 & 91.3 & & 2.91 \\
\hline
\end{tabular}

TABLE 6: Breakthrough study results.

\begin{tabular}{|c|c|c|}
\hline Compound & Mass $(\mathrm{m} / \mathrm{z})$ & Breakthrough time (s) \\
\hline Benzene & 78 & 75 \\
\hline Carbon tetrachloride & 117 & 350 \\
\hline (E/Z)-1,2-Dichloroethylenes & 96 & 75 \\
\hline Ethyl chloride & 66 & 25 \\
\hline Methylene chloride & 84 & 50 \\
\hline Trichloroethylene & 97 & 125 \\
\hline Tetrachloroethylene & 166 & $>575$ \\
\hline Toluene & 92 & 150 \\
\hline Vinyl chloride & 62 & 50 \\
\hline$o, m$, p-Xylenes & 106 & $>575$ \\
\hline
\end{tabular}

consisting of $10 \mathrm{~s}$ line purge and $15 \mathrm{~s}$ concentrator fill, breakthrough times for each analyte were determined. Not unexpectedly, the results summarized in Table 6 demonstrate that the most volatile compounds have the shortest breakthrough times and the need for a multibed microconcentrator.

\section{Conclusion}

A portable robust GC/MS fitted with a TriBed microconcentrator has been developed for identification and accurate quantitation of volatile organic compounds at the ppbv level. The method described herein adheres to the performance criteria described by the US EPA for the monitoring of indoor air. The collection and analysis of samples are accomplished in $3 \mathrm{~min}$; concentrations of sub-ppbv analytes may be obtained with longer sampling times. It will be necessary to demonstrate that the instrument performs as expected in on-site monitoring of indoor air samples, but the present results suggest that the present analytical method should prove to be a powerful tool for the environmental monitoring of indoor air.

\section{Acknowledgments}

The authors are grateful to Mr. Marvin Thompson of the University of Connecticut for his helpful guidance. This work was supported by a grant from the Syracuse Center of Excellence. 


\section{References}

[1] K. B. Hoddinott and A. P. Lee, "The use of environmental risk assessment methodologies for an indoor air quality investigation," Chemosphere, vol. 41, no. 1-2, pp. 77-84, 2000.

[2] J. D. Spengler and K. Sexton, "Indoor air pollution: a public health perspective," Science, vol. 221, no. 4605, pp. 9-17, 1983.

[3] N. A. Fitzpatrick and J. J. Fitzgerald, "An evaluation of vapor intrusion into buildings through a study of field data," Soil and Sediment Contamination, vol. 11, no. 4, pp. 603-623, 2002.

[4] S. Chowdhury and S. L. Brock, "Indoor air inhalation risk assessment for volatiles emanating from light nonaqueous phase liquids," Soil and Sediment Contamination, vol. 10, no. 4, pp. 387-403, 2001.

[5] T. E. McHugh, P. C. De Blanc, and R. J. Pokluda, "Indoor air as a source of VOC contamination in shallow soils below buildings," Soil and Sediment Contamination, vol. 15, no. 1, pp. 103-122, 2006.

[6] L. Turczynowicz and N. I. Robinson, "Exposure assessment modeling for volatiles - towards an Australian indoor vapor intrusion model," Journal of Toxicology and Environmental Health A, vol. 70, no. 19, pp. 1619-1634, 2007.

[7] S. D. Phillips, G. R. Krieger, R. B. Palmer, and J. C. Waksman, "Solvents and vapor intrusion pathways," Clinics in Occupational and Environmental Medicine, vol. 4, no. 3, pp. 423-443, 2004.

[8] A. T. Hodgson, K. Garbesi, R. G. Sextro, and J. M. Daisey, "Soil-gas contamination and entry of volatile organic compounds into a house near a landfill," Journal of the Air and Waste Management Association, vol. 42, no. 3, pp. 277-283, 1992.

[9] S. Huo, B. Xi, H. Yu, L. He, S. Fan, and H. Liu, "Characteristics of dissolved organic matter (DOM) in leachate with different landfill ages," Journal of Environmental Sciences, vol. 20, no. 4, pp. 492-498, 2008.

[10] P. F. Sanders and I. Hers, "Vapor intrusion in homes over gasoline-contaminated ground water in Stafford, New Jersey," Ground Water Monitoring and Remediation, vol. 26, no. 1, pp. 63-72, 2006.

[11] I. Hers, R. Zapf-Gilje, L. Li, and J. Atwater, "The use of indoor air measurements to evaluate intrusion of subsurface VOC vapors into buildings," Journal of the Air and Waste Management Association, vol. 51, no. 9, pp. 1318-1331, 2001.

[12] B. M. Eklund and M. A. Simon, "Concentration of tetrachloroethylene in indoor air at a former dry cleaner facility as a function of subsurface contamination: a case study," Journal of the Air and Waste Management Association, vol. 57, no. 6, pp. 753-760, 2007.

[13] W. T. Winberry, N. T. Murphy, and R. M. Riggin, "Compendium methods for the determination of toxic organic compounds in ambient air," U.S. EPA Report EPA/600/4-84041, EPA, 1997.

[14] W. A. McClenny and M. W. Holdren, "Compendium Method TO-15, Determination of volatile organic compounds in air collected in specially-prepared canisters and analyzed by gas chromatography/mass spectrometry," U.S. EPA. Report EPA/625/R-96/010b, EPA, 1999.

[15] E. A. Woolfenden and W. A. McClenny, "Compendium Method TO-17. Determination of volatile organic compounds in ambient air using active sampling onto sorbent tubes," U.S. EPA Report EPA/625/R-96/010b, EPA, 1997.
[16] C.-W. Chung, M. T. Morandi, T. H. Stock, and M. Afshar, "Evaluation of a passive sampler for volatile organic compounds at ppb concentrations, varying temperatures, and humidities with 24-h exposures. 2. Sampler performance," Environmental Science and Technology, vol. 33, no. 20, pp. 3666-3671, 1999.

[17] Massachusetts Department of Environmental Protection agency (MDEP), "Indoor air contaminants comparison table," 2007, http://www.mass.gov/dep/cleanup/iaq02.doc.

[18] H. Lin, C. Deng, and X. Zhang, "Fast field analysis of shortchain aliphatic amines in water using solid-phase microextraction and a portable gas chromatograph," Journal of Separation Science, vol. 31, no. 18, pp. 3225-3230, 2008.

[19] M. Jia, J. Koziel, and J. Pawliszyn, "Fast field sampling/sample preparation and quantification of volatile organic compounds in indoor air by solid-phase microextraction and portable gas chromatography," Field Analytical Chemistry and Technology, vol. 4, no. 2-3, pp. 73-84, 2000.

[20] P. A. Smith, D. Koch, G. L. Hook et al., "Detection of gas-phase chemical warfare agents using field-portable gas chromatography-mass spectrometry systems: instrument and sampling strategy considerations," Trends in Analytical Chemistry, vol. 23, no. 4, pp. 296-306, 2004.

[21] T. Maeda, S. Arakawa, and T. Tanaka, "Introduction of the portable GC/MS,” Kogyo Yosui, vol. 469, pp. 48-50, 1997.

[22] H. Sekiguchi, K. Matsushita, S. Yamashiro et al., "On-site determination of nerve and mustard gases using a fieldportable gas chromatograph-mass spectrometer," Forensic Toxicology, vol. 24, no. 1, pp. 17-22, 2006.

[23] E. Davoli and L. Motti, "Hapsite portable GC/MS instrument," Laboratorio, vol. 12, pp. 14-18, 1999.

[24] H. L. C. Meuzelaar, J. P. Dworzanski, N. S. Arnold, W. H. McClennen, and D. J. Wager, "Advances in field-portable mobile GC/MS instrumentation," Field Analytical Chemistry and Technology, vol. 4, no. 1, pp. 3-13, 2000.

[25] J. D. Fair, W. F. Bailey, R. A. Felty, A. E. Gifford, B. Shultes, and L. H. Volles, "Method for rapid on-site identification of VOCs," Journal of Environmental Sciences, vol. 21, no. 7, pp. 1005-1008, 2009.

[26] Ö. O. Kuntasal, D. Karman, D. Wang, S. G. Tuncel, and G. Tuncel, "Determination of volatile organic compounds in different microenvironments by multibed adsorption and shortpath thermal desorption followed by gas chromatographicmass spectrometric analysis," Journal of Chromatography A, vol. 1099, no. 1-2, pp. 43-54, 2005. 


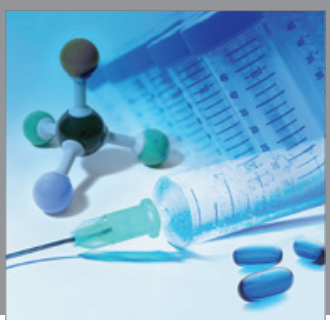

International Journal of

Medicinal Chemistry

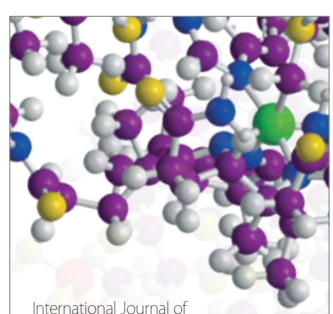

Carbohydrate Chemistry

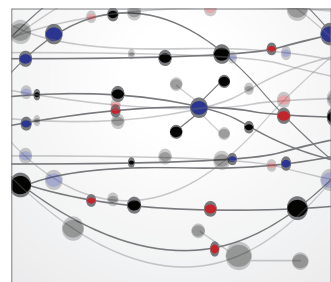

The Scientific World Journal
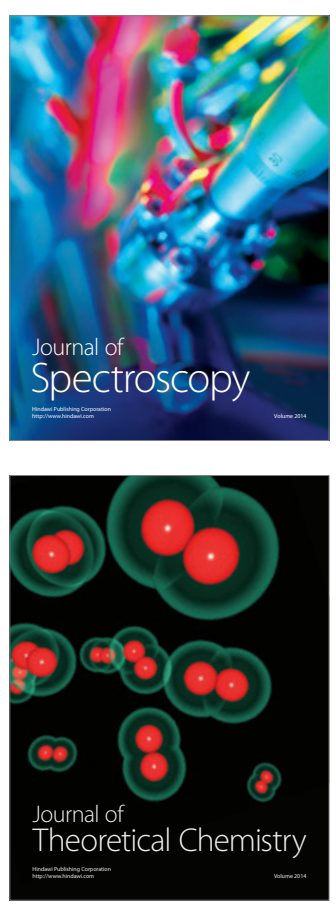


Submit your manuscripts at

http://www.hindawi.com
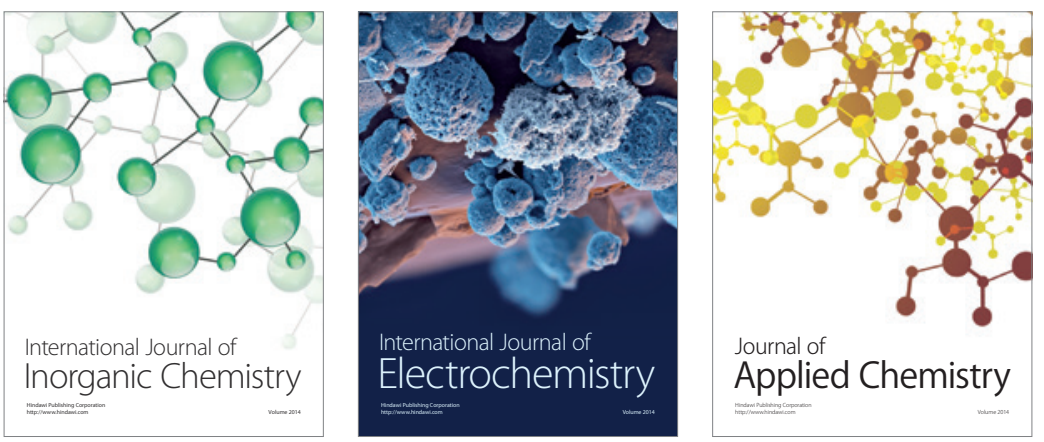

Journal of

Applied Chemistry
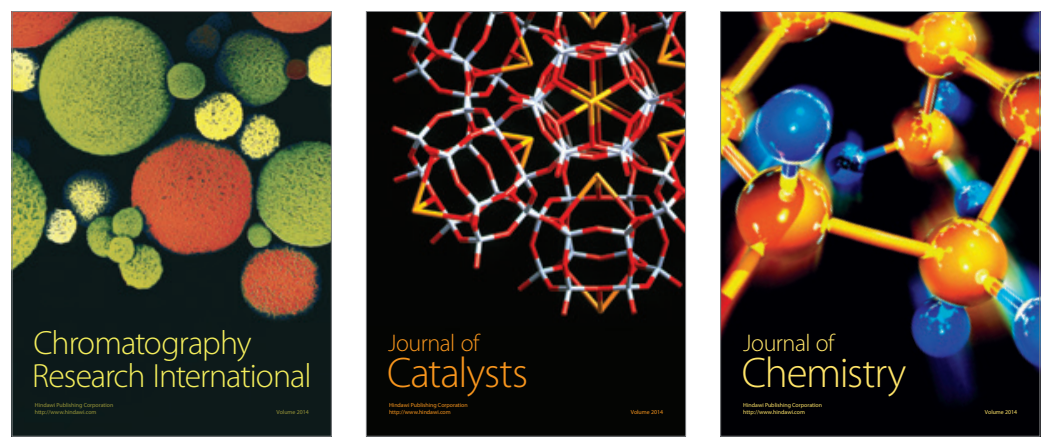
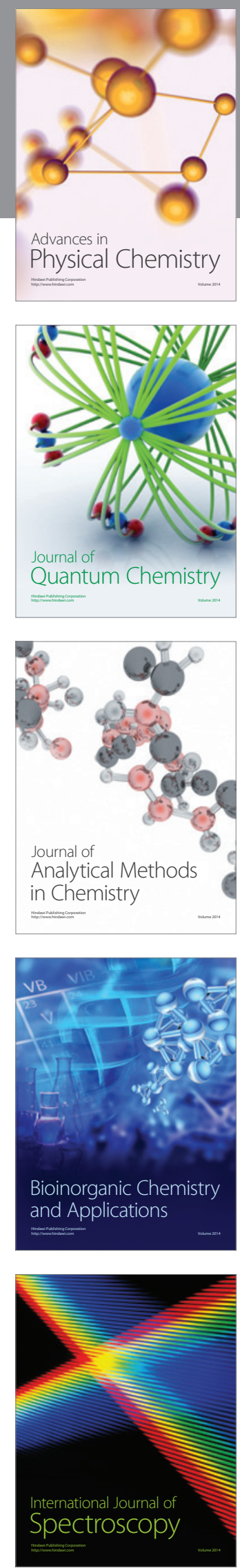